\title{
Who Am I on Facebook? Usage and Motivation Through User Eyes
}

\author{
Gabriel Artur Marra e Rosa, Benedito Rodrigues dos Santos \\ Catholic University of Brasília, Brasília-DF, Brazil
}

\begin{abstract}
This article discusses different modes of using Facebook and the motivation for its users. The analysis aims to clarify how and why users might resort to one or more usage modes when joining this social network and emphasizes the relationship between interactions mediated by this social network and user identity. For this we conducted semi-structured interviews with 10 young Facebook users—five males and five females—all residing in Brasília-DF, Brazil. The results obtained were compared with those found in previous research. We used theoretical derived data from social psychology and socio-cultural anthropology for the data analysis and conducted an accurate literature review. The conclusion goes beyond the distinction between motivation and usage and expresses a critical analysis of Facebook usage purposes thus indicating widespread use that can extend to other specifics depending on the interests of the participants. Furthermore, there is motivation behind Facebook which is not yet mentioned in existing research which attracts enthusiasts to Facebook and is directly related to the issue of identity in the contemporary world.
\end{abstract}

Keywords: Facebook, usage, motivation, identity, contemporary world

\section{Introduction}

The present article refers to empirically qualitative based research aimed at challenging foregone categorizations in relation to the usage and motivations behind people using the social network site Facebook. Previous studies have confirmed that Facebook facilitates social connections between people. However, the specific activities and motives that influence the use of this social network remain unclear. As Yang and Brown (2013) confirmed, there is a clear distinction between motive and action despite their being close. This distinction is generally expressed in literature by the difference between what one does on social networks and why.

This study examined the association between usage and modes of motivation on the concept that different motivations can influence people into using Facebook. Secondly, on the notion that users can apply distinct usage mode according to motivation and personal ends they find in the way they use the site. In fact, we believe that beyond motivation, there are reasons behind using social networks like Facebook which researchers tend to consider as motivation or simply do not observe. Due to this, we hereby intend to provide a description and an analysis to distinguish motivation, ends, and types of use through user opinions. Our focus is particularly on identity issue motivation for using social networks in the contemporary world.

Gabriel Artur Marra e Rosa, Ph.D. candidate, Institute of Psychology, Catholic University of Brasilia. Benedito Rodrigues dos Santos, Ph.D., professor, Institute of Psychology, Catholic University of Brasilia. 
The topic of the impact of the new media and globalization process in identity construction (Bauman, 2005; Hall, 2006) has recently been central to social network related debates. The term "self-presentation" (Manago, Taylor, \& Greenfield, 2012) has been applied to express the way people use sites like Facebook to reveal personal attitudes and to give explicit self-descriptions through such discussions. In our opinion, however, these authors do not highlight the connection between usage modes, motivation and ends to which the identity issue is related. As Zhao, Grasmusck, and Martin (2008) demonstrated, there is an identity construction process on Facebook anchored in the relationships seen today. For this reason, this paper provides a critical distinction of the categories usage, motivation, and ends to understand how the identity question permeates the interactional dynamics of Facebook as a way of people presenting themselves to others and being present in the "continuun" between the social network sites and the real life.

We therefore conjectured that the motivations of using sites like Facebook-and the ends users find for such - unleash certain types of usage which they are simultaneously able to combine and develop. This phenomenon carries the issue of modern identity as its propellant. Hence when describing, differentiating, or analyzing them in a critical way, we should rethink interaction dynamics in social network sites like Facebook in order to recognize possible repercussions of this phenomenon in the contemporary world as well as on user subjectivity.

\section{Use and Motivation Inputs From Literature}

In general, the use of SNS (social networking sites) has been associated with student social connectivity (Reich, 2010) even with the vast number of different users worldwide. Consequently, most research is focused on understanding what kinds of activities students perform on network sites and what motivates them in such. However, there is a consensus among researchers concerning a yet evolving typology of Facebook activities (Yang \& Brown, 2013).

Firstly, one of the most common activities involves electronic interactions with friends, such as posting, commenting, or replying messages (Junko, 2012; Lenhart \& Madden, 2007). Secondly, there are the so-called voyeuristic actions sometimes referred to as "lurking” or "Stalking” (e.g., Junco, 2012; Subrahmanyam, Reich, Waechter, \& Espinoza, 2008). Thirdly, a common type of activity is focused on self-presentation and is related to revealing personal attitudes and interests or giving explicit self-descriptions (Boyd, 2007; Toma \& Hancock, 2012). Finally comes gaming which is related to playing games and taking quizzes (Junco, 2012).

Lampe, Ellison, and Steinfield (2006) identify two types of Facebook usage. The first one called "social searching" is related to the use of finding and learning more about acquaintances outside the network or even offline. The second one- "social browsing”-refers usage for meeting people and organizing events through the network. The authors concluded the motivations governing the use of Facebook as keeping in touch with old and new friends, plus observing actions, beliefs, and interests of groups followed.

Considering these usage and motivation concepts when analyzing usage types and what motivates people to use Facebook, we initially perform a conceptual distinction in which we consider motivation the reason participants use Facebook and then the purpose behind using it. This conceptual distinction is based on the analysis of Stafford, Stafford and Schkade (2004) which defined Internet use and motivation as the "how" and the "why".

Golder, Wilkinson, and Huberman (2007) argue that for upkeep, friendships require effort and investment, so messages on social networks are used to maintain friendship ties. Improved capital is the main motivation 
for such as is also claimed by Ellison, Steinfield, and Lampe (2007). Based on this statement, we deduce that the increase in capital is one of the main purposes motivating individuals to participate in any social network (Fasano, 2010) including virtual ones. However, it seems to us that there are other motivations and ends especially regarding the different uses of social networks on the Internet.

Joinson (2008) noted that there are seven motivations that cause certain types of usage according to feedback the user obtains to one or more of their usages-typically social connection, shared identities, photographs, content, social investigations, social network surfing, and status updates. The motivations and usage distinguished by Joinson (2008) outline a prototypical model regarding correlation between usage and motivation. It seems important to note that all the motivations he mentioned except "content" implicitly allude to representations of identities because they are linked to the possibility of seeing identity aspects (traits and characteristics) related to other users. With emphasis on social investigations, social network surfing and shared identities, we deduce that the question of identity permeates the motivations and usage described by Joinson (2008) and operates implicitly in Facebook use.

Bumgarner (2007) found that people's main motivation for using the website is social activity. The author argues that there is no sole motivation for using Facebook and that the network can satisfy a broad variety of purposes. Bumgarner (2007) highlights the usage he detected as Friend functions, personal information, practical information, regulatory functions, groups, events, and miscellaneous features. The results obtained by Bumgarner (2007) reveal that Facebook has many utilities, generates varied usage, and provides social activities both within and outside its scope. Consequently, we agree with the author and believe that most accesses are motivated by social activity which is the reason behind the existence of the website. However, we realize that the usages described by the author-especially the first four-detail a listing of Facebook devices, functions, and features which are functionalities of the website and not different usages carried out on them.

We recognize that the devices and their respective functions and resources motivate website usage. However, these are set features and irrespective of the changing usage each user is able to perform. Throughout the survey we conducted, we noted widespread use of social networking websites tending to be most extensive among participants and coming in different forms. We therefore argue that interactions occur through the exposure of tastes and cultural preferences, profile exploration (self-descriptions, photos, and murals) as well as through the exposure of ideas, creating feelings, interaction and entertainment through the functions and features offered on Facebook. We call this kind of usage mediated interaction because of these peculiarities.

Besides this usage, in the course of the investigation, we found other types that tend to develop based on the first and which converge with and diverge from those described by Bumgarner (2007) and Joinson (2008). Indeed, we performed a mapping of the main uses found and ranked them as follows:

(1) Mediated interaction;

(2) Activism;

(3) Personal/professional publicity;

(4) Relationships.

However, it is worth mentioning the fact that the means of using this website varies among users and is not limited to just one specific usage per user. Consequently, it follows that participants perform varied uses and that the reasons of such are consistent with the motivations and interests of enthusiasts, promoting the use of available network resources in a particular way. 


\section{Method}

In this research, we used the technical and theoretical instrument from qualitative research methodology based on the Symbolic Interactionism Approach (Flick, 2009). The procedure for data collection followed the prerogatives of semi structured interviews (Groeben, 1990). Ten young Facebook users were selected as participants—five females and five males—all residing in Brasilia and surrounding areas. All names herein are aliases.

The interviews sought opinions on subject matter as well as meanings and subjective senses (manifested and latent ones) concerning use and motivation. For this, we prepared a script to guide researchers during the interviews based on open and closed questions. The analysis of the material obtained in interviews had the interpretative based on social psychology and sociocultural anthropology. The technique for analyzing the data obtained was sense zones or "zonas de sentido" (González-Rey, 2011). It focused on the sense and meanings concerning activities shared by the interviewees upon identification by the researcher when analyzing the discourses in relation to the theory in conjunction with perceptions gathered along the research process.

\section{Mediated Interaction}

The usage type - hereby categorized as mediated interaction—is related to interaction through comments, video postings, pictures and the possibility of establishing and maintaining contacts as well as exploring other user profiles. In this modality, we highlight the features "share" and "like" which allow participants to forward, give opinions, approval or consent (through the option "like") or even disagree in relation to their own or other's postings.

This is the most common type of use by fans on Facebook and tends to unfold into specific modalities of use where the main characteristics involve mediated interaction through information diffusion, cultural tastes and preferences as well as humor. The following opinions of interviewees Alfredo and Max respectively were therefore important in factually supporting our theoretical proposal:

Facebook has led people away from using e-mail or led them to use e-mail less and to find more amusement with Facebook, like an e-sprawl of jokes and funny things... I found it cool because people share more, you have more people and each one sends a different thing — a joke or a political video. It's a very broad medium and you choose what you like and "like" it.

I really like posting songs and jokes, I browse the internet blogs and stuff. I'm not very keen on writing but I'm reading a lot of these things and when I finally find something interesting or something funny, I put it on Facebook for everyone to see, like "look what a cool thing I've found”!

The participants' answer shows that postings gather opinions from users, making it a way for people to interact and keep in touch through the use of information, humor, and exchanges. Thus, an important attribute of mediated interaction is that users express their tastes and preferences as well as expressing their ideas and feelings through what they post and publish. It follows that all participants know that what is posted will be viewed by others and we therefore highlight a tendency to select what will be published on the network. Consequently, publications are often associated to those who publish them, promoting the idea of identification and the tendency to represent themselves through shared postings as stated by interviewee Francisco about these comments and postings:

It's important because it's open for others to see - so a person comes and makes a point on my timeline and makes a statement related to me and it somehow relates me to everyone who is there. 
Francisco reveals that each post on his wall is directly related to him and to others. To Pinheiro (2008), identity is replaced in this virtual environment by subjectivity, modulated by choices that are displayed and shared. The aforementioned author's intention is of great importance for demonstrating that on social networks, exposure of preferences is a requirement that is often related to one's presentation to others according to what one likes or dislikes which would supposedly identify the character behind such publications or postings.

Magalhães and Paiva (2009) indicate that the publication of choices for which identification occurs on networks suggests a transient expression of identity. For these authors, this is an opportunity to make choices, reconsider previous choices, to try to conciliate conflicting and incompatible demands and to distance oneself from the risks inherent to instability hovering over real life relationships.

On the other hand, we recognize that routinely mediated interaction also comes from the publication of daily activities, feelings, emotions, and thoughts as well as the publication of a person's location. This occurs frequently according to the opinion of interviewees Carla and Ana:

It often became a form of "virtual diary” but of course I don't go in there publishing very intimate details, more like- “God give me courage today and give me wisdom ...”, it takes on a form of a diary but also of a prayer without exposing myself too much.

I like to express how I feel on a daily basis. Sometimes I put something there to let people know how I am. It may be a thought, an opinion or even a video or a song I like.

This occurrence shows that this use of the network also serves as a diary for which publishing and viewing is permitted to all connected. Nicolaci-da-Costa (2005) noted that in virtual environments such as social networks, individuals gain knowledge about themselves and their uniqueness as they write about themselves and receive feedback. Similarly, the author stated that due to these feedbacks, participants undergo adjustments in a constant process of revision, being themselves the only source of integration of multiple exposures and possible multiple feedbacks.

Another relevant characteristic of mediated interaction refers to resources that enable one to find old friends on Facebook. Mocellin (2007) argues that social network users are also interested in recovering the past - trying to find long lost friends. To Mocellin (2007), this is not only a way to recover old friendships but also a way to reshape personal identities as proposed by Giddens (2002) — based on a construction supported by the appropriation of the past to build the future. On this appeal, interviewee Roberto says: "It was a benefit because I could find old friends that I did not usually meet in person. I have contact with childhood friends on the network".

According to Mocellin (2007), in addition to providing reshaping of identity through appropriation of the past, this phenomenon in this environment allows us to experience all the identities we would like to have as also noted by Nicolaci-da-Costa (2005) in relation to the virtual world. In this perspective, Mocellin (2007) and Nicolaci-da-Costa (2005) stated that this trial-expression is witnessed through the expression of preferences and ideas, and includes the people with whom we interact on the network which is extremely important in this environment. To Magalhães and Paiva (2009), identities are permeated by current transience—-formed and continuously reshaped-bringing with it the challenge of exercising freedom to our multiple identities without losing ourselves on the way, and consolidating one profound identity that represents us. We can thus say that social networking users employ tactics to represent themselves in daily life. This representation is facilitated by mediated interaction in virtual networks as Mônica expresses: 
Because it's easier. You are there on your computer and no-one's looking-You have time to architect your words and your text—which you don't have in live transmission because when live, a person can contest you and you clash.

In our opinion and in short, Facebook provides resources for its own use by mediated interaction where the representation of "self" (Goffman, 2009) supervenes through a facade (publications or postings) and a scenario (the social networking website). Behind the scenes (outside Facebook), the correlation is in focus between what is public and what is felt, thought, and wished.

\section{Activism}

Apart from being a way of promoting debate and social mobilizations, activism is described by its constitution of modality of expression and its dissemination of political, religious, cultural, and ethical ideals through Facebook. This type of use also takes place in virtual communities and tends to unite groups in similar situations. It resembles mediated interaction though differs from the latter in its relation to the intention of publishing viewpoints which are considered controversial and generate discussions on sensitive issues, interacting on behalf of personal concepts and issues of public importance. This is clear in the words of interviewee Guilherme: "I like to post news about politics and events in Brazil and worldwide. I think it's important for people to show their ideas and a way of contributing to democracy”.

In this type of use, one sees user tendency to take a stance regarding the facts while other users show their ideas for all to express opinions about the events. As a result, we turn again to Castells (1999) to identify the presence of project identity whose objective is to redefine the positioning of participants in society and consequently seek the transformation of the social structure. Activism, as a mode of use of Facebook is based on the search for ideals and projects in common in order to cause some sort of change (whether to participants' opinions or social organization itself).

In activism, there is an increased exposure to social identity facet elements which are somehow undoubtedly related to the facet of personal identity. We therefore believe that website users in some way demonstrate an affinity to what is published. This consequently establishes a network within the network generally providing conformation of groups or communities. In fact, we analyzed the characteristics of collective usage in groups and communities as arranged in groups by Bumgarner (2007) or shared identities by Joinson (2008). We came to the conclusion that they hold some correlation with what is hereby called activism. However, as Mônica explains, the groups derived from accomplished uses and user interests:

... but groups-only if I intend to actually participate. In the former students group, we schedule meetings and publish job offers... the NGO group is for us to communicate and debate through it; and the Park group is linked with these others.

As the aforementioned interviewee expressed, groups and communities can fulfill different functions including trivial things compared to what we call activism usage type. For example, there may be groups for cosmetic tips, movie discussions or simply of friends or acquaintances as noted by Bumgarner (2007). A careful reading of this testimony actually allows us to observe the manifestation not only of project identity but also those of legitimation and resistance (Castells, 1999) due to the proliferation of diverse communities and groups in these areas which creates a direct relationship between social identity and participation in groups and communities.

In this line of reasoning, it seems consistent to assume that due to the decentralization of cultural references (Hall, 2006) and liquefaction of structures and social institutions as a result of the so-called 
postmodernity (Bauman, 2005), there is a search for the identification of a supposed consolidation of identities. These findings may be related to the generation of a process of re-tribalization (Mafesolli, 1987) in which urban tribes are constituted in the virtual environment and which in our opinion represent us through identification and give us a sense of identity.

Recuero (2008) clarifies that the affiliation to groups and communities is not only to discuss ideas, schedule events, or the propagation of propositions but also to the identification or assertion of identities. Actually, a double movement in the use of activism type is evident-On the one hand, the users protest and participate in debates and social mobilizations in order to legitimize, resist, or create a projective social identity, while on the other hand, there is a relentless pursuit for ideals and sociocultural references to represent their personal identities. Mônica explicitly reiterated this saying: "In this, people keep creating schools of thought. When I post it, many 'likes' appear and you think: 'Cool, this is my niche, my group’”.

Mônica's story demonstrates that schools of thought are constituted in the so-called offline life on social networks that users join by choice. It is worth clarifying that these groups do not significantly differ from face-to-face ones. The only difference rests in the characteristics of the virtual world. Furthermore, we do not exclude the possibility that there are different groups and consequently discrimination and segregation between groups and individuals belonging to different groups on the network. Once again we resume the issue of the importance of otherness for the conformation of identities due to the fact we can experience a sense of continuity or flow of the so-called self (Deschamps \& Moliner, 2009) by assessing similarity or difference.

Social psychology assesses the phenomenon of group formation among humans as a way found by individuals to organize and develop their knowledge about themselves, surroundings, and others. The correlation with identity is established through the categorization process which involves other psychological processes tending to organize the surroundings into categories namely groups of people, objects and, events linked by similarity or equivalence thus determining individuals' intentions, attitudes, and actions (Tajfel, 1981).

The categorization process performs the function of organization and systematization of the world thereby influencing the individual's personal perceptions about information supplied by the environment. For Turner, Hogg, Oakes, Reicher, and Wetherell (1987), the individual undergoes a process of self-categorization on three levels. On the first (superordinate), the individual is considered as a human being and makes comparisons between humans and other species. On the second (intermediate level), the individual is self-categorized as a member belonging to certain groups and makes intergroup comparisons. On this level, a differentiation is established between groups of belonging ("inner group") and external ("outer group”). On the last level (subordinate), the individual is considered a singular person and compares self with other group members.

According to Turner et al. (1987), the intermediate level of self-categorization is what strengthens the facet of social identity while the subordinate level is what strengthens the facet of personal identity. We therefore assume that even before joining, participants of Internet social networks already had their groups of belonging and differentiation and new groups derived from the set of Facebook users in association on the network. Consequently, the process of self-categorization can occur from the intermediate level as well as the subordinate level and establish itself in correlation between groups and online/offline communities.

This usage type occurs through this correlation and users can reevaluate their membership to certain groups as well as the facets of their personal and social identities through interaction with other participants. 
Subsequently, we note that the activism usage mode can bring implications on individual identities which will be further explored in relation to other usage types and the supposed motivations that trigger different usage modes on Facebook.

\section{Personal/Professional Publicity}

The use of Facebook for personal/professional publicity is characterized by posting phrases, images, videos, and links related to blogs and personal or professional websites. Such disclosures, along with offering products and services on the website enable the promulgation of this information to existing contacts. According to interviewee Guilherme, this occurs as follows: "I publish the links for my blog and work-related websites so that people can have access, know about my work and comment”.

In relation to usage focused on the publicity of professional identity, studies have shown that social networking websites such as Facebook facilitate the management of professional identity although they make it difficult to differentiate between this identity and the personal one (Dimicco \& Millen, 2007). The participants of this research claim that there are resources and tactics on Facebook that facilitate the management of identities. Max expresses his opinion on this and Alfredo reinforces our assertion:

My Facebook nowadays is much divided-It's separated into a thousand groups and divided so that each person can see only what's related to that group. For example, my college friends see one thing while those at work see another. Those from the neighborhood see yet another. Each sees what concerns them.

I do not put my professional activities on it even though my profile exposes my profession. It is there to tell jokes.

Despite the use of tactics and available resources, we recognize that there may be difficulty in managing identities due to possible interference from other users connected to the network. Aspects omitted on the user profile can be brought into public (Hewitt \& Forte, 2006). In our opinion, the management opportunity which separates the professional identity from the personal one in this context is the creation of differentiated profiles-each relating to the respective identity one intends to publish. Nevertheless, in the personal/professional publicity usage type, there may be confluences of aspects related to both spheres of identity through subtle manifestations or postings from other users. We therefore recognize the effectiveness of Facebook in publishing offers of services and products thus triggering the search for solutions through this website as Carla expresses:

...you see, in the beginning, it was just entertainment—seeking friends and such like. But over the past few months I have sought employment on Facebook. I have a college friend who sends me job listings and I have sought tutoring on Facebook. When someone among my family or friends needs a maid or something, I look for one on Facebook. It became much more than entertainment. It became a place where you can find anything.

In this account, there is a convergence of modalities of usage that involve mediated interaction through Facebook. The interviewee comments that she uses the website for fun and seeking friends. She stresses that she also uses Facebook to seek services. It appears that on this social network the types of use converge and meet not only the need for interaction and social activity but also demands for services and products. This encourages the spread of advertising offers mingled with publications related to personal aspects. Moreover, there are announcements of events, parties, and social gatherings through the website, making it an effective way to publish personal and professional information. Personal/Professional publicity type of use can thus permeate other usage modalities, also reflecting the underlying marketing logic which in turn can affect the representation that individuals make of themselves on Facebook. 


\section{Relationships}

The usage type known as relationships is associated to the use of the social network to form or maintain relationships, flirt or seek sexual/romantic partnerships. Alfredo's opinion reveals this characteristic: "The main advantage besides entertainment is meeting people—women or people we see around".

Turkle (1999) pointed out the possibility of starting a relationship over the Internet regardless of distance, concluding that this is one of the first attractions to mediated relationships through the virtual environment in which the Internet social networks are implanted. Donnamaria and Terzis (2009) noted that this type of bond comprises two stages. The first is characterized by the identification of mutual values and desires. The second has the particularity of confirming these desires and values in real life.

Knowing that people relate outside Facebook as well as via the website we can state that in relationship usage mode, stages may be inverted because participants may have met personally prior to having contact on Facebook and vice versa. However, as corroborated by Donnamaria and Terzis (2009), within the networks there is a stage of mutual identification for common values and desires as Alfredo confirms: "I think people end up mingling or not; it just happens. Each expresses his motives and people think: 'This one's an idiot', or 'I really liked what he posted' so you can involve or stay out”.

What the user expresses on the network can provoke other users or keep them away. It should be considered that the user can select, create, omit and conceal certain aspects of their identity which is more difficult in face to face relationships. This way, the relationships usage type suggests that there is a greater manipulation of data related to identities for self-presentation following standards of socially desirable identities (Zhao et al., 2008).

The selection of characters tends to be more discerning in this type of use, regardless of whether publications are true or sincere or not. We therefore deduce that in the relationships usage type there is a meticulous management regarding profile development as well as information and photo posting. We highlight Ana's point of view about this feature:

You realize that on the profiles of single people there are more updates, photos at parties with lots of good-looking people and on cool occasions. Generally, the person appears to be more outgoing and is willing to go out and meet new people.

Ana's opinion reinforces the assertion that motivation and interest users have to have one or more usage types. Accordingly, information socially viewed with suspicion and physical aspects considered contrary to beauty ideals — which can be grounds for discrimination and stigmatization-tend to be hidden or concealed on Facebook. In this usage type, we emphasize the trend of adjusting features and information that will be published to represent identities although this does not preclude what Donnamaria and Terzis (2009) called the second stage - the confirmation or otherwise of these identities in real life.

\section{Specific Motivations}

Bumgarner (2007) identified possible motivations for the use of this social network as social utility, directory, voyeurism, herd instinct, collection and connection, personal expression, and initiating relationships.These motivations are directly related to the usage types previously developed here. For example, this relationship emerges from the associations between mediated interaction usage type and social utility motivation, the relationship usage type and initiating relationships motivation. However, Bumgarner (2007) demonstrates other motivations such as directory and collection and connection which we have also found in 
our research as expressed by Francisco:

It's like a place where I keep my contacts and gives me some security. Often, you go to a place where you do not know anything or anyone and need to ask or get in touch, and it is a very good resource. I think it's a little treasure—-something in which you have a good portion of your world where you can go and look at any time.

In our opinion, the motivations classified as directory and collection and connection are based on the features provided by these resources Facebook has which in fact motivate users but do not constitute as main motivations for using this social network. What he called herd instinct (the herd effect) seems to us to be one of the main motivations of joining and using Facebook as Mônica expressed:

A friend of mine kept telling me about Facebook substituting Orkut as a new social network. She said that Facebook was more internationalized and that Orkut was much more a Brazil thing. Then I started to see that people were migrating from one network to the other and that was when I did too.

The fact of having the largest number of members motivates the use of a website and hence social activity tends to be intensified due to the number of people signed up. The primary motivation for using the Internet social networks is the social activity they provide as noted by Bumgarner (2007). We also suggest that the secondary motivation is the fact that each user can find, register, and maintain contact with others (friends, acquaintances, or others) who are signed up on the network. That is to say, in addition to providing social activity, the Internet social networks have features expressed in the directory and collection and connection motivations whose main features are the ease, speed and efficiency of meeting and managing contacts and connecting to people as indicated by Joinson (2008) with the concepts of social investigations and social network surfing.

We evaluated that users register on Facebook primarily with the motivation to follow friends (the herd effect), participate in social activities and enjoy the functionality that the website provides. Consequently, as of the moment that users find the tools, features, and functionalities of Facebook we think there are other usage motivations. For this reason, we suggest that the basic motivation of social activity triggers the herd effect and the use of the functionality the website offers therefore generating the mediated interaction usage type. Indeed, new motivations may appear due to the use of devices from the website and the social activity that is developed there. Consequently, they may be space for new usage types such as activism, personal/professional publicity and relationships.

Secondly, new motivations may appear. The user tends to expand the use made and devote more time to the use of the website which may lead to the intensification of the motivations that Bumgarner (2007) called personal expression and voyeurism. Based on the results obtained in the current study, we deduce that two motivations mentioned above-personal expression and voyeurism—are implicit since the user's registration on the website and tend to become one of the main motivations for using Internet social networks to the extent that resources and tools for such are made available.

This assumption comes from the conjecture that social activities and features the Internet social networks offer are also available in offline life in some media and on the Internet itself. That is, website use is indeed motivated by the functionalities and the social activities Facebook provides. However, the major motivating factors for using this virtual social network include the possibilities of using it to express oneself and getting understanding from others plus the novelty of knowing about others at a distance and comparing oneself to them via a virtual environment. Hence, there are two essential motivations that encourage the use of Facebook 
which were excellently pointed out by Bumgarner (2007)—namely personal expression and voyeurism.

We conclude that the personal expression and voyeurism motivations are directly related to identitary processes in terms of self-categorization (Turner et al., 1987) and identification (Vandenbos, 2010). Such processes are performed through interaction between members of the group of Facebook users. Indeed, we suggest that there is another motivation behind the use of social networking websites which is the attempt to discover who we are or our identities. In this sense, this motivation carries different usage types, different stories, different identifications, subsequent feelings and emotions.

From this perspective, we resume the work by Nicolaci-da-Costa (2005) where in these so-called virtual environments, people present themselves with different identities and characteristics. In other words, they can build different stories (whether true, sincere, anonymous or not) about themselves and disseminate knowledge about themselves and their uniqueness to the extent that they write about themselves and have feedback on these writings. Similarly, the author goes further by noting that due to the multiple feedbacks they get on writing about themselves, users submit their definitions of themselves to a constant process of revision. Furthermore, by exposing themselves to so many spaces, realities, experiences, and feedbacks, they are themselves the only possible source of integration from the results of these multiple exposures and feedbacks.

\section{The Ends}

After analyzing the usage types, we found the motivations expressed by the participants we sought to identify the purpose of the social network sites in the lives of people who use them. In this, Max offered us an "idea":

These social networks are like this.... you use them to maintain contact with the person and at the end of the day, the purpose is another. (What?) (laughter) That depends on each person. There are those who use it to get in with people, those who use it to maintain contact with people they know and there are people who use it for meeting new people while others for making their reputation (verbal information).

The said interviewee's answer corroborates statements on an aspect relative to the objectives. According to him the site can be used to maintain contacts, interrelate with others, get to know other people, and build a reputation. Considering this response and the analysis that we carried out on usage and motivations we can mention other objectives beyond those mentioned above, like creating a normal diary, using Facebook as a daily account, sharing information and knowledge as well as tastes and cultural preferences, offering and seeking services, events and products, and even debating subjects of interest.

In terms of objectives (or rather-why use Facebook?), we recognize that all previously mentioned objectives are of great relevance to users. Despite this, based on the inference that one of the principal motivations behind different uses of this social network site is the attempt to discover who we are and that there are counter interests in the interactions mediated by the site, we sustain the suggestion that Facebook is used above all with the purpose of negotiating identities. To substantiate our conjectures we again highlight Max's statement:

Network can be well thought... in the case of the social network we are not speaking about a specific network. We have so many networks that we decided to speak of this one in particular which is Facebook and for me a new form of communication with a marketing appeal because people can demonstrate and sell their product, be it an appeal for their self-esteem or... because it's this... we have our friends and always try to stand out in our social group so on the network it is not different. We are always looking for certain plugs saying "I’m different”, “I’m special”, "I’m here”, “I’m alive and I exist”. 
This participant says that there is a marketing appeal and a market logic which involves the publicity and the consumption on Facebook. We consider that this logic is due to the social organization that in turn models ${ }^{1}$ and propitiates the development of an identity negotiation process in a peculiar way in the virtual world. Hence, considering the strategies chosen by the site, the daily negotiation tactics by users and further based on the theory De Certeau (1988), we sustain that in a certain way, influenced by the motivation of trying to discover who we are and by the interests of each user, participants interact from not only using the resources and Facebook tools to negotiate their identities but also from identity models marketed through interactions and posts.

On the other hand, while they negotiate their identities on this site, the individual users of this social network service act on behalf of social causes (activism) and personal aspects (publicity/personal/professional and relationships), and they placate gatherings whose objective is to interfere in social organization (Bourdieu, 1977) and which can, in our opinion reverberate in subjectivities.

Our analysis about uses, modalities, and finalities leads us to recognize the existence of a true identity negotiation process on Facebook through the influence of the market and of the social organization in user identities and through the genuine expression of individuals who use Facebook to make themselves present according to their interests. Effectively, a reciprocal negotiation is created based on counter interests which in our opinion, foments the expression of identities, feelings, and emotions through the processes of identification and categorization.

One notes that the representations users make of themselves on the network include the exhibition of tastes and preferences and on certain occasions, emotions, and feelings which can also be expressive and tend towards the connotation of representation of the "me". As a result, we suggest that these representations are like a digital "me” (Turkle, 1995) and possess performance characteristics and histrionic attitudes (Goffman, 2009) that seek on the one hand to represent an identity (according to the participant's interests and socially established standards) and on the other hand through feedback, to get to know the identity negotiation process this environment generates.

As demonstrated, we sustain that representations are negotiated and consumed through identification processes and categorization as well as from their correlates (emotions, feelings, and ideas) to the degree that interactions on the site provide the capacity to express oneself and of knowing how others express themselves in the Facebook user group.

\section{Conclusions}

In the course of this analysis, it was found that there are three fundamental motivations that cause people to become adept to Facebook - the so-called herd effect (joining, belonging and not being "outcast" from this network user group), the social activity that develops through it, and taking advantage of the resources Facebook provides. Finally, we emphasized the existence of an underlying motivation- the attempt to discover who we are - which in our opinion also undoubtedly includes knowing who other people are.

Of these four motivations we highlighted the last as the foremost-though not explicitly admitted by users. In this perspective, we consider that this motivation orientates many of the activities performed on the website although not explicitly stated and can be added to other user motivations and interests and deployed into four

\footnotetext{
${ }^{1}$ According to Livingstone (2009), "Within this discursive context of negotiation and experimentation, identities are expressed online not as free-floating, individual activity but as embedded in and shaped by specific social and technological conditions” (p. 117).
} 
types of usage-mediated interaction, activism, personal/professional publicity and relationships.

This study allowed us to corroborate the thesis that there is an identity negotiating process on Facebook (Rosa \& Santos, 2013) which occurs through the selection of identity traits and characteristics which are represented to each audience and in each circumstance according to conflicting interests in mediated interactions and in the continuity established between what happens inside and outside of the so-called virtual world of the Internet and the social networks.

For future research, it is necessary to consider the possibility of analyzing the effects of this modus how people present themselves in their subjectivities on the social networks. This presence is a result of the combination of the personalized user profile and of posts in general (texts, comments, photos, and other images) that we call identity negotiation. In effect, in a broader context of the academic-social concerns over the impacts of the use of information and communication technology in social interaction-more specifically with what has become known as aestheticism of the self in social network users-Our contributions could help articulations between the concepts of use, motivation and purpose and the results obtained in research whose focus is the analysis of the possible repercussions of this phenomenon.

\section{References}

Bauman, Z. (2005). Identidade. Rio de Janeiro: Zahar.

Bourdieu, P. (1977). Outline of a theory of practice (R. Nice, Trad.). Cambridge: Cambridge University Press.

Boyd, D. (2007). Why youth (heart) social network sites: The role of networked publics in teenage social life. In D. Buckingham (Ed.), MacArthur foundation series on digital learning-Youth, identity, and digital media volume. Cambridge, M.A.. Retrieved from: http://www.danah.org/papers/WhyYouthHeart.pdf

Bumgarner, B. A. (2007). You have been poked: Exploring the uses and gratifications of Facebook among emerging adult. First Monday, 12. Retrieved from http://firstmonday.org/ojs/index.php/fm/article/view/2026

Castells, M. (1999). O poder da identidade (The power of identity). São Paulo: Paz e Terra.

De Certeau, M. (1988). The practice of everyday life. (S. Rendall, Trad.). California: University of California Press.

Deschamps, J. C., \& Moliner, P. (2009). A identidade em psicologia social: Dos processos identitários às representações sociais (The identity in social psychology: from identity processes to social representations). Petrópolis, R.J.: Vozes.

Dimicco, J. M., \& Millen, D. R. (2007). Identity management: Multiple presentations of self in Facebook. Proceedings of the 2007 International ACM Conference on Supporting Group Work (pp. 383-386). New York: ACM. Retrieved from http://citeseerx.ist.psu.edu/viewdoc/download?doi=10.1.1.127.6500\&rep=rep1\&type=pdf

Donnamaria, C. P., \& Terzis, A. (2009). O amor caiu na rede: Sobre a procura e a evolução de vínculos amorosos na Internet (Love fell into the net: About the search and the evolution of the loving bonds in the Internet). Revista SPAGESP, 10(2), 45-49.

Ellison, N. B., Steinfield, C., \& Lampe, C. (2007). The benefits of Facebook “friends”: Social capital and college students' use of online social networks sites. Journal of Computer-Mediated Comunication, 12, 1143-1168.

Fasano, L. (2010). Tejiendo redes: El papel de las redes sociales en la salud y en el bienestar (Weaving Networks: The role of social networks in health and welfare). Buenos Aires: Gran Aldea.

Flick, U. (2009). Introdução à pesquisa qualitativa (An introduction to qualitative research) (J. E. Costa, Trad., 3rd ed.). Porto Alegre: Artmed.

Giddens, A. (2002). Modernidade e identidade (Modernity and self-identity: Self and society in the late modern age). Rio de Janeiro: J. Zahar.

Goffman, E. (2009). A representação do eu na vida cotidiana (The presentation of self in everyday life). Petrópolis: Vozes.

Golder, S. A., Wilkson, D., \& Huberman, B. A. (2007). Rhythms of social interaction: Messaging within a massive online network. Proceedings of the International Conference on Communities and Technologies, 3 (pp. 41-66). East Lansing, M.I.. Retrieved from http://link.springer.com/chapter/10.1007\%2F978-1-84628-905-7_3

González-Rey, F. L. (2011). Pesquisa qualitativa em Psicologia: Caminhos e desafios (Qualitative research in psychology: Challenges and paths). São Paulo: Cengage Learning. 
Groeben, N. (1990). Subjective theories and the explanation of human action. In G. R. Semin, \& K. J. Gergen (Eds.), Everyday understanding social and scientific implications (pp. 19-44). London: Sage.

Hall, S. (2006). A identidade cultural na pós-modernidade (The question of cultural identity). Rio de Janeiro: DP\&A.

Hewitt, A., \& Forte, A. (2006). Crossing boundaries: Identity management and student/faculty relationships on the Facebook. Proceedings of the CSCW. Banff, Alberta, Canada. Retrieved from http://andreaforte.net/HewittForteCSCWPoster2006.pdf

Joinson, A. N. (2008). "Looking at”, “looking up” or "keeping up with” people?: Motives and uses of Facebook. Proceedings of the SIGCHI Conference on Human Factors in Computing Systems (pp. 1027-1036), Florence, Italy. New York: ACM. Retrieved from http://citeseerx.ist.psu.edu/viewdoc/download?doi=10.1.1.168.3722\&rep=rep1\&type=pdf

Junco, R. (2012). The relationship between frequency of Facebook use, participation in Facebook activities, and student engagement. Computer \& Education, 58(1), 162-171.

Lampe, C., Ellison, N. B., \& Steinfield, C. A. (2006). Face(book) in the crowd: Social searching vs. social browsing. Proceedings of CSCW (pp. 167-170). New York: ACM. Retrieved from http://dl.acm.org/citation.cfm?id=1180875.1180901

Lenhart, A., \& Madden, M. (2007). Social networking websites and teens: An overview. Pew Internet and American Life Project. Retrieved from http://www.pewinternet.org/Reports/2007/Social-Networking-Websites-and-Teens.aspx

Livingstone, S. (2009). Children and the Internet. Cambridge: Polity Press.

Mafesolli, M. (1987). O tempo das tribos: O declínio do individualismo nas sociedades de massa (The time of the tribes: The decline of individualism in mass societies). Rio de Janeiro: Forense.

Magalhães, M., \& Paiva, C. C. (2009). Estilos de identidade nas redes sociais de relacionamento (Styles identity in social networking sites). Cultura Midiática, 2, 1-9.

Manago, A. M., Taylor, T., \& Greenfield, P. M. (2012). Me and my 400 friends: The anatomy of college students' Facebook networks, their communication patterns, and well-being. Developmental Psychology, 48(2), 369-380.

Mocellin, A. (2007). Internet e identidade: Um estudo sobre o website Orkut (Internet and Identity: A study on the Orkut Website) Tese, 3, 100-121.

Nicolaci-da-Costa, A. M. (2005). Primeiros contornos de uma nova "configuração psíquica” (First contours of a new "psychic configuration”). Caderno Cedes, 25, 71-85.

Pinheiro, M. A. (2008, November). Subjetivação e consumo em sites de relacionamento (Subjectivity and consumption on social networking sites). Comunicação, Mídia e Consumo, 5(14), 103-121.

Recuero, R. (2008). Estratégias de personalização e sites de redes sociais: Um estudo de caso da apropriação do fotolog.com (Customization strategies and social networking sites: A case study of the appropriation of fotolog.com). Comunicação, Mídia e Consumo, 5, 35-36.

Reich, S. M. (2010). Adolescents' sense of community on MySpace and Facebook: A mixed-methods approach. Journal of Community Psichology, 38(6), 688-705.

Rosa, G. A. M., \& Santos, B. R. (2013). Facebook e as nossas identidades virtuais. Brasília: Thesaurus.

Stafford, T. F., Stafford, M. R., \& Schkade, L. L. (2004). Determining uses and gratifications for the Internet. Decision Sciences, 2, 259-288.

Subrahmanyam, K., Reich, S. M., Waechter, N., \& Espinoza, G. (2008). Online and offline social networks: Use of social networking sites by emerging adults. Journal of Applied Developmental Psychology, 29, 420-433.

Tajfel, H. (1981). Human groups and social categories: Studies in social psychology. Cambridge, UK: Cambridge University Press.

Toma, C. L., \& Hancock, J. T. (2012). What lies beneath: The linguistic traces of deception in online dating profiles. Journal of Communication, 62, 78-97.

Turkle, S. (1995). Life on the screen: Identity in the age of the Internet. New York: Simon \& Schuster.

Turkle, S. (1999). Fronteiras do real e do virtual (Boundaries of real and virtual). Revista Faecos, 11, 117-123.

Turner, J. C., Hogg, M., Oakes, P. J., Reicher, S. D., \& WetherellL, M. S. (1987). Rediscovering the social group. Oxford: Blackwell.

Vandenbos, G. R. (Org.). (2010). Dicionário de Psicologia APA (APA dictionary of psychology). Porto Alegre: Artmed.

Yang, Chia-Chen, \& Brown, B. (2013). Motives for using Facebook, patterns of Facebook activities, and late adolescents' social adjustment to college. Journal of Youth \& Adolescence, 42(3), 403-416.

Zhao, S., Grasmusck, S., \& Martin, J. (2008). Identity construction on Facebook: Digital empowerment in anchored relationships. Computer in Human Behavior, 24, 1816-1836. 